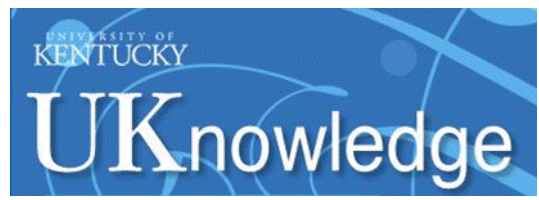

University of Kentucky

UKnowledge

Biosystems and Agricultural Engineering Faculty Publications

\title{
Recalibration Methodology to Compensate for Changing Fluid Properties in an Individual Nozzle Direct Injection System
}

\author{
Joe D. Luck \\ University of Nebraska - Lincoln \\ Scott A. Shearer \\ The Ohio State University \\ Brian D. Luck \\ University of Wisconsin - Madison \\ Michael P. Sama \\ University of Kentucky, michael.sama@uky.edu
}

Follow this and additional works at: https://uknowledge.uky.edu/bae_facpub

Part of the Agriculture Commons, and the Bioresource and Agricultural Engineering Commons

Right click to open a feedback form in a new tab to let us know how this document benefits you.

\section{Repository Citation}

Luck, Joe D.; Shearer, Scott A.; Luck, Brian D.; and Sama, Michael P., "Recalibration Methodology to Compensate for Changing Fluid Properties in an Individual Nozzle Direct Injection System" (2016). Biosystems and Agricultural Engineering Faculty Publications. 140.

https://uknowledge.uky.edu/bae_facpub/140

This Article is brought to you for free and open access by the Biosystems and Agricultural Engineering at UKnowledge. It has been accepted for inclusion in Biosystems and Agricultural Engineering Faculty Publications by an authorized administrator of UKnowledge. For more information, please contact UKnowledge@lsv.uky.edu. 


\section{Recalibration Methodology to Compensate for Changing Fluid Properties in an Individual Nozzle Direct Injection System}

\section{Digital Object Identifier (DOI)}

https://doi.org/10.13031/trans.59.11521

\section{Notes/Citation Information}

Published in Transactions of the ASABE, v. 59, issue 3, p. 847-859.

(C) 2016 American Society of Agricultural and Biological Engineers

The copyright holder has granted the permission for posting the article here. 


\title{
RECALIBRATION METHODOLOGY TO COMPENSATE FOR CHANGING FLUID PROPERTIES IN AN INDIVIDUAL NOZZLE DIRECT INJECTION SYSTEM
}

\author{
J. D. Luck, S. A. Shearer, B. D. Luck, M. P. Sama
}

\begin{abstract}
Limited advancement of direct injection pesticide application systems has been made in recent years, which has hindered further commercialization of this technology. One approach to solving the lag and mixing issues typically associated with injection-based systems is high-pressure individual nozzle injection. However, accurate monitoring of the chemical concentrate flow rate can pose a challenge due to the high pressure, low flow, and changing viscosities of the fluid. A methodology was developed for recalibrating high-pressure chemical concentrate injectors to compensate for fluid property variations and evaluate the performance of this technique for operating injectors in an open-loop configuration. Specific objectives were to (1) develop a method for continuous recalibration of the chemical concentrate injectors to ensure accurate metering of chemicals of varying viscosities and (2) evaluate the recalibration method for estimating individual injector flow rates from a system of multiple injectors to assess potential errors. Test results indicated that the recalibration method was able to compensate for changes in fluid kinematic viscosity (e.g., from temperature changes and/or product variation). Errors were less than $3.4 \%$ for the minimum injector duty cycle $\left(D C_{i}\right)($ at $10 \%)$ and dropped $0.2 \%$ for the maximum $D_{i}$ (at $90 \%$ ) for temperature changes of up to $20^{\circ} \mathrm{C}$. While larger temperature changes may be expected, these test results showed that the proposed method could be successfully implemented to meet desired injection rates. Because multiple injectors would be used in commercial deployment of this technology, a method was developed to calculate the desired injector flow rate using initial injector calibration factors. Using this multi-injector recalibration method, errors ranged from $0.23 \%$ to $0.66 \%$ between predicted and actual flow rates for all three injectors.
\end{abstract}

Keywords. Pesticides, Precision agriculture, Spraying equipment, Variable-rate application.

$\mathrm{T}$ The development of variable-rate pesticide application technologies has received significant attention in recent years and could provide solutions to various spray application errors. Direct chemical injection, developed as an alternative to tank mixing, is one type of variable-rate technology that has been extensively tested over the years. For commercially available systems, the chemical concentrate and carrier are typically pressurized separately and combined in a mixing chamber ahead of the spray boom. Direct injection application systems can

Submitted for review in August 2015 as manuscript number MS 11521; approved for publication by the Machinery Systems Community of ASABE in February 2016.

The information reported in this article (No. 15-05-074) is part of a project of the Kentucky Agricultural Experiment Station and is published with the approval of the Director. Mention of trade names is for informational purposes only and does not necessarily imply endorsement by the Kentucky Agricultural Experiment Station.

The authors are Joe D. Luck, ASABE Member, Assistant Professor, Department of Biological Systems Engineering, University of NebraskaLincoln, Lincoln, Nebraska; Scott A. Shearer, ASABE Fellow, Professor and Chair, Department of Food, Agricultural and Biological Engineering, The Ohio State University, Columbus, Ohio; Brian D. Luck, ASABE Member, Assistant Professor and Extension Specialist, Department of Biological Systems Engineering, University of Wisconsin-Madison, Madison, Wisconsin; Michael P. Sama, ASABE Member, Assistant Professor, Department of Biosystems and Agricultural Engineering, University of Kentucky, Lexington, Kentucky. Corresponding author: Joe D. Luck, 206 L.W. Chase Hall, University of Nebraska-Lincoln, Lincoln, NE 68583-0726; phone: 402-472-1488; e-mail: jluck2@unl.edu. be subdivided into two basic types: in-line injection systems, which inject the chemical concentrate upstream of multiple nozzles or boom sections, and nozzle injection systems, where the chemical is injected at or near individual nozzles.

\section{DIRECT IN-LINE INJECTION SYSTEMS}

Vidrine et al. (1975) introduced an in-line injection system as a means of compensating for ground speed changes. This system was capable of varying the chemical concentrate metered into the carrier as the ground speed changed; however, problems associated with this early method included greater pesticide deposition variability compared to conventional tank mix methods as well as transient errors in the application rate resulting from operating speed changes. Similar systems were developed and tested by others (Larson et al., 1982; Reichard and Ladd, 1983) for metering pesticide concentrations proportional to the travel speed prior to nozzle discharge.

Research carried out to quantify the errors often found the systems to be inadequate. Way et al. (1992) found that field application errors were higher for direct injection sprayers compared to conventional tank mix sprayers under simulated conditions. Sudduth et al. (1995) reported that controller and chemical injection pump responses were adequate for use in a variable-rate system; however, the transport delay times (up to $21.0 \mathrm{~s}$ ) for chemical concentra- 
tion response after ground speed changes were deemed unacceptable for this commercially available system ( $\mathrm{Ra}-$ ven SCS-700) to perform well. Following these tests, the same company developed a "carrier control" system, which also varied the rate of carrier in response to ground speed changes or target rate, to be used in combination with the original direct injection system. Subsequent studies found that this additional technology still produced concentration errors that contributed to application error; however, errors were reduced compared to the original system without carrier control (Steward and Humburg, 2000). Qui et al. (1998) conducted a feasibility study for using direct injection for variable-rate herbicide application. They developed a simulation model to study the effects of several factors on system performance. Reducing time delays in the system could be achieved by moving the mixing location closer to the boom or using smaller-diameter chemical/carrier lines to reduce line volumes, provided the pressure drop was not appreciably increased.

Zhu et al. (1998a, 1998b) used the Raven SCS-700 direct injection system to test a sampling system for determining lag time and mixture uniformity. While the goal of the study was not to evaluate the direct injection system but rather the sampling platform, results indicated that reducing the boom line diameter reduced the lag time of the sprayer system. A later study by Zhu et al. (1998c) confirmed that reducing the boom line diameter reduced system lag time with the Raven SCS-700 system; however, decreasing the number of active nozzles on the boom did not significantly affect lag time.

Womac et al. (2002) conducted tests using fixed-ratio diluents-driven pumps for variable concentration injection and found large pressure fluctuations (CVs up to 32.4\%). Pressure variations were reduced by increasing the hose length downstream of the pump, but accurate variable concentration would likely require closed-loop control of the chemical inputs as well as improved pressure control. Anglund and Ayers (2003) evaluated a direct injection system and found the lag time for the active ingredient (chemical concentrate) was between 15 and $55 \mathrm{~s}$ based on the carrier flow rate.

\section{DiRECT NozZLE INJECTION SYSTEMS}

Tompkins et al. (1990) conducted a study regarding the effects of injection location (immediately upstream and downstream of the pump and at each nozzle) on response time and chemical concentration variation of the nozzle discharge. Results indicated a decrease in the transient time required to produce a uniform chemical concentration at the nozzle as the injection point moved closer to the nozzle. A similar study was performed by Sumner et al. (2000) to test string collectors aimed at evaluating direct injection systems. Results indicated that the proximity of the injection point to the nozzles had an impact on lag time, which significantly increased with the number of nozzles served by each injection point. The lag and charge times of the system agreed well with the values calculated based on boom line diameter and carrier velocities. Miller and Smith (1992) developed and tested a prototype direct injection nozzle where the chemical was injected via a metering ori- fice immediately upstream of the nozzle. The nozzle-tonozzle $\mathrm{CV}$ was $3.4 \%$ for a low metering orifice pressure differential $(70 \mathrm{kPa})$ and $2.2 \%$ for a high metering orifice pressure differential $(483 \mathrm{kPa})$. Spray pattern uniformity was also evaluated, with CVs ranging from $2.9 \%$ to $0.4 \%$ (from low to high differential pressure) for flat fan nozzles, while the CVs for flooding tip nozzles ranged from $1.5 \%$ to $1.1 \%$ (from low to high differential pressure). Koo and Kuhlman (1993) suggested that the best method for precise chemical application while minimizing negative impacts to spray characteristics (pattern and droplet size spectra) would be to use direct injection of the chemical with nozzle flow control. The results indicated that the variable flow nozzle (by varying the input orifice) could result in turndown ratios of 3.6:1. Tests conducted by Koo and Kuhlman (1993) did not include any evaluation of the combined direct injection system with the variable flow nozzle.

Rockwell and Ayers (1996) developed and tested a variable-rate, direct nozzle injection, agricultural field sprayer to determine spray pattern uniformity and response time. Results of the study indicated that spray pattern uniformity was not significantly different from that of conventional tank-mixed sprayer systems, while the average time constant was 2.5 s. Vondricka and Schulze Lammers (2009a) developed a system for intermittent, patch spraying activities. The focus of their study was to determine if carrier switching (on and off) affected the injection process and spray pattern establishment. Results indicated that the reaction time of the carrier valve averaged $0.015 \mathrm{~s}$, while desired spray patterns developed in around $0.004 \mathrm{~s}$ under the selected carrier, injection, and air valve pressure settings (Vondricka and Schulze Lammers, 2009a). Further testing of a similar system resulted in suggestions for improved mixing chambers and nozzle injection control processes to optimize system performance (Vondricka and Schulze Lammers, 2009b). One of the major similarities of the aforementioned systems is a concern that chemical/carrier mixing is not adequate prior to discharge from the nozzle. Most of these systems have studied chemical injection at pressures of less than $700 \mathrm{kPa}$. More recently, Luck (2010) developed a high-pressure direct injection nozzle that injected a simulated chemical concentrate (at 8.27 MPa) into a mixing chamber at the nozzle using an electronic directacting solenoid valve. Results indicated that operating the solenoid valve at frequencies between 5 and $8 \mathrm{~Hz}$ (duty cycle from $10 \%$ to $90 \%$ ) produced the best results with a system time constant of $0.3 \mathrm{~s}$. Chemical concentrate mixing was also found to be acceptable across the nozzle pattern, which was believed to be a result of injecting the chemical at such a high pressure.

The common problem with most of the previously described systems has been lag time and adequate mixing of the chemical concentrate prior to nozzle discharge. Ramsdale et al. (2003) showed that increasing the spray volume to glyphosate ratio resulted in less efficacy of the material. Therefore, proper chemical concentrations must be maintained to ensure proper weed elimination with this herbicide. Two potential solutions suggested to help alleviate these problems have been to vary the carrier flow rate (Koo and Kuhlman, 1993) and inject the chemical concentrate at 
higher pressures (Luck, 2010). Combining the benefits of these two systems may hold the key for creating the ultimate spray delivery system that reacts quickly to system changes or application needs while ensuring proper mixing of the chemical prior to application.

\section{Direct InJeCtion Chemical Metering}

One important factor that must be considered when discussing direct chemical injection for agricultural sprayers is the accuracy of the metering system. As discussed by Gebhardt et al. (1984), the chemical injection flow rates should be accurately measured and controlled to ensure that proper application rates are delivered by the system. Temperature changes were found to affect the density and viscosity of the pesticides tested as well as the response of the drag-body flowmeter used during the study. The results of the study indicated that flowmeter accuracy was improved when the temperature was constant and calibration constants were used for each combination of pesticide and temperature (Gebhardt et al., 1984).

Chi et al. (1988) developed a system for measuring and controlling the flow rate of an agricultural chemical. Further improvements were made to this system by Chi et al. (1989), who designed and tested an electro-mechanical feedback system for chemical injection control. The system was determined to be effective for fluid viscosities from 90 to $300 \mathrm{mPa} \cdot \mathrm{s}$ with flow rates ranging from 3 to $20 \mathrm{~mL} \mathrm{~s}^{-1}$. Frost (1990) developed a pesticide injection metering system that used a water metering pump to displace the chemical from an injection cylinder. The volume of water displaced from the cylinder was considered equal to the amount of chemical metered into the carrier stream. While the system was said to have performed well, further development of such a system has not been attempted.

Way et al. (1991) tested three flowmeters for use with liquid herbicides. The thermal, turbine, and piston flowmeters had linearities of $\pm 77 \%, \pm 45 \%$, and $\pm 8.7 \%$, respectively, when used to measure flow rates of an emulsion herbicide formulation. The study suggested that flowmeters would need to be calibrated for different temperatures of the herbicide to maintain errors below 5\% (Way et al., 1991).

Hughes and Frost (1985) presented an extensive review of agricultural spray metering principles and research along with strengths and weaknesses of the systems discussed. With regard to chemical concentrate metering, the study echoed much previous research indicating that temperature effects on viscosity could result in reduced accuracy of most flowmeters. It also suggested that electromagnetic flowmeters, while expensive, could maintain accuracy with changes in the chemical properties.

Cochran et al. (1987) conducted tests to determine the physical properties of three oils (soybean, peanut, and sun spray 7-N) and combinations of those oils mixed with insecticides (Dursban and Lorsban). Results of the study indicated that increasing the insecticide concentration in the oils decreased the effects of temperature on viscosity. However, in general, temperature increases were still shown to reduce viscosity for the oil-insecticide mixtures. Luck (2010) found that the viscosity of glyphosate ranged from 10 to $45 \mathrm{mPa} \cdot \mathrm{s}$ for temperatures ranging from $45^{\circ} \mathrm{C}$ to $5^{\circ} \mathrm{C}$, respectively. Further development of flow control systems for direct injection of agricultural chemicals will need to address the effects of temperature on the viscosity of the chemical and, ultimately, how this affects the performance of a flowmeter to ensure metering accuracy. Commercial adoption rates for direct injection systems have been low in general; however, they offer other advantages, including chemical/carrier separation and sprayer clean-out, that may make them more appealing in the future.

\section{GOALS AND OBJECTIVES}

The successful development of an individual-nozzle direct injection-based pesticide application system depends on accurate metering of the chemical during treatments. The overall goal of this research was to develop a method for recalibrating high-pressure chemical concentrate injectors to compensate for fluid property variations and evaluate the performance of this technique for operating the injectors in an open-loop configuration. The proposed system would allow initial calibrations to be modified based on subsequent flow measurements to adjust for changes in injected fluid viscosities. The specific objectives were to (1) develop a method for continuous recalibration of the chemical concentrate injectors to ensure accurate metering of chemicals of varying viscosities and (2) evaluate the recalibration method for estimating individual injector flow rates from a system of multiple injectors to assess potential errors.

\section{Materials AND MethodS INJECTION AND METERING SYSTEM SETUP}

Rhodamine WT (RhoWT) fluorescent red dye (R-00298-16, Cole Parmer, Vernon Hills, Ill.), glycerin (99.5\% USP, veg-based, KIC Chemical, Inc., New Poltz, N.Y.), and deionized (DI) water were mixed to create a solution for simulating glyphosate, a popular pesticide. The simulated glyphosate mixture for testing will henceforth be referred to as the "chemical" or "chemical concentrate." Therefore, $138.1 \mathrm{~kg}$ of glycerin was mixed with $51.1 \mathrm{~kg}$ of DI water in the concentrate reservoir. The RhoWT dye served as the tracer for future testing of chemical concentrations based on absorbance measurements. From the results presented by Luck et al. (2012), a minimum concentration of 2000:1 (glycerin/DI water to RhoWT dye) was found to be acceptable for absorbance measurements. This concentration was selected because the simulated chemical would be further diluted when injected into the carrier stream. Therefore, $94.6 \mathrm{~g}$ of RhoWT dye was mixed with the glycerin/DI water solution in the concentrate reservoir.

The chemical concentrate was supplied to the system by a fixed-displacement plunger pump (3XU49, Dayton Electric Manufacturing Co., Lake Forest, Ill.). The pump was driven by a hydraulic motor (101-1749-009, Eaton Corp., Cleveland, Ohio) powered by a laboratory hydraulic test stand and operated at $1750 \mathrm{rpm}$. The system accumulator consisted of $9.0 \mathrm{~m}$ of $5.08 \mathrm{~cm}$ diameter high-pressure hy- 


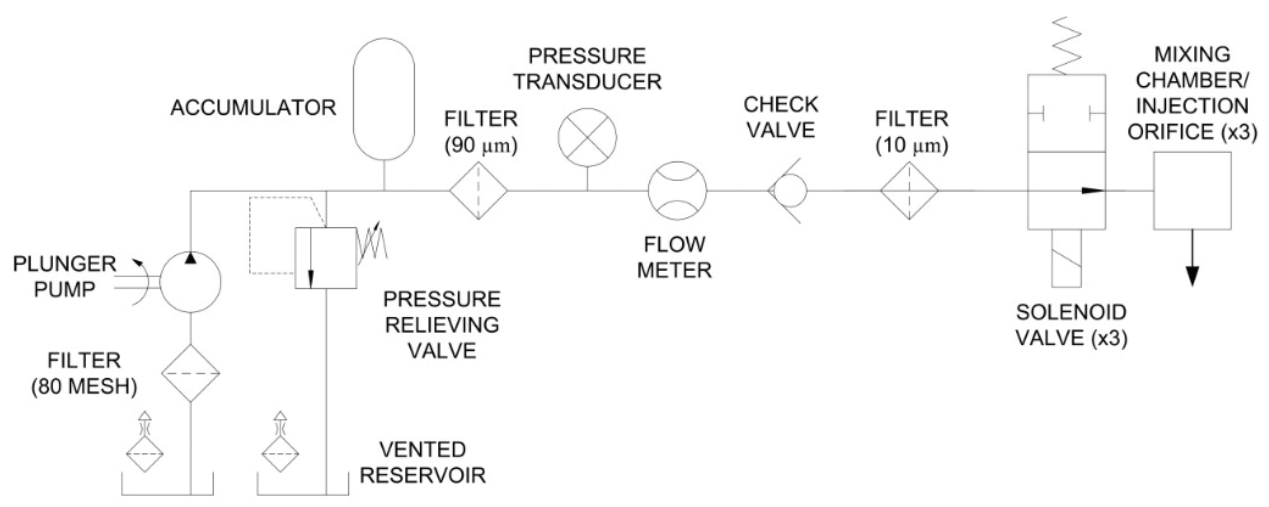

Figure 1. Circuit schematic of chemical concentrate injection and metering system.

draulic hose (FC323-16 AQP, Eaton Corp., Cleveland, Ohio) rated for $20.7 \mathrm{MPa}$. The injection system pressure was controlled with a high-pressure regulating (HPR) valve (6815-1/2, Spraying Systems Co., Wheaton, Ill.). The chemical concentrate pressure was constantly monitored using a calibrated pressure transducer (PX309-2KG5V, Omegadyne, Inc., Sunbury, Ohio) powered via a 12 VDC supply with an output signal of 0 to $5 \mathrm{VDC}$ proportional to system pressure over a range of 0 to $13.8 \mathrm{MPa}$.

System flow rate was monitored using a gear flowmeter (JVM-12KG, AW-Lake Co., Franksville, Wisc.) with a digital display (RT-Ex15, AW-Lake Co., Franksville, Wisc.). An 80-mesh inline filter (39908-1, Delavan AgSpray Products, Mendota Heights, Minn.) was placed in the circuit between the reservoir and pump. Two additional inline filters (9052V-90, Arrow Pneumatics, Broadview, Ill.) were installed prior to the pressure transducer $(90 \mu \mathrm{m}$ filter) and solenoid valves (10 $\mu \mathrm{m}$ filter). The line was split to service three 24 VDC direct-operating solenoid valves (71216SN2BL00N0C111C2, Parker Fluid Control Division, New Britain, Conn.) that were connected inline directly in front of the mixing chambers. Each mixing chamber was fabricated from aluminum and housed an injection orifice made of brass. The injection orifice was $0.343 \mathrm{~mm}$ in diameter. From this point on, the term "injector" is used to describe the combination of a solenoid valve and injection orifice. Detailed schematics showing the dimensions of these two system components can be found in the appendix material from Luck (2012). A circuit schematic of the chemical concentrate injection system is shown in figure 1 .

\section{INJECTION AND METERING CONTROL SYSTEM}

A schematic of the microcontroller circuit for the injec- tion system is shown in figure 2. Individual injector duty cycles $\left(D C_{i}\right)$ chosen for testing ranged from $10 \%$ to $90 \%$ at input frequencies of 5 to $7 \mathrm{~Hz}$. This range of duty cycles provided a linear response in the flow rate from the injection orifice. The injection system was controlled by a combination of programs developed for a personal computer (Microsoft Visual Studio 2010) and a microcontroller (PIC18F2585, Microchip Technology Inc., Chandler, Ariz.). The control program enabled separate control of the three solenoid valves during trials. Input to the user interface required a desired injector (i.e., combination of a solenoid valve and injection orifice) duty cycle $\left(D C_{i}\right)$ and frequency for operation of the solenoid valves. The desired $D C_{i}$ and frequency were sent via serial output to the microcontroller (fig. 2). The microcontroller program used a lookup table to determine how long to pulse the output signals (to the relays) on and off based on these user inputs. The pulse signals (truth table logic, or TTL) were then output to the relays (G4ODC5, Opto 22, Inc., Temecula, Cal.), which were supplied with 24 VDC from an external power supply. The relay output was then wired directly to the solenoid valves with a common ground throughout the system.

\section{InJECTION TeSt Procedures AND DATA AnAlysiS}

Tests were conducted to evaluate the physical properties of the chemical concentrate. Specifically, the viscosity was evaluated over a range of temperatures using a Saybolt viscometer. A sample of the chemical concentrate was placed in the viscometer (200 F196, Cannon Instrument Co., State College, $\mathrm{Pa}$.), and time measurements at temperatures ranging from $19^{\circ} \mathrm{C}$ to $41^{\circ} \mathrm{C}$ were taken. Based on the calibration sheet, the kinematic viscosity of the chemical was estimat-

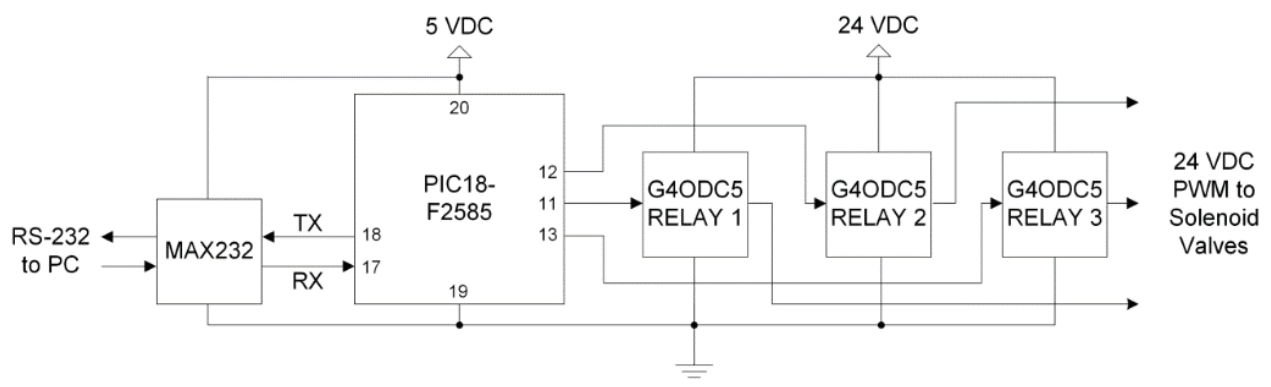

Figure 2. Schematic of microcontroller circuit pinouts used for injection control. 
ed by multiplying the time by the viscometer constant $\left(0.1024 \mathrm{cSt} \mathrm{s}^{-1}\right)$. In addition, the system temperature was monitored during sample collection using a digital thermometer. This was done to determine the potential temperature rise in the system as the chemical concentrate was passed through the injectors. Sources aside from environmental conditions may contribute to temperature rise; for instance, the pump and HPR valve would likely contribute to temperature increases.

Much of the work presented in this study involved fully developed laminar pipe flow and a Newtonian fluid. As such, a few fundamental equations provide the basis for the resulting relationships. The Hagen-Poiseuille equation (eq. 1) describes laminar flow in smooth-walled conduits:

$$
Q=\frac{\pi \Delta P R^{4}}{8 \mu L}
$$

where

$Q=$ flow through the pipe $\left(\mathrm{m}^{3} \mathrm{~s}^{-1}\right)$

$\Delta P=$ pressure drop through the pipe $(\mathrm{MPa})$

$\mu=$ dynamic viscosity $\left(\mathrm{kg} \mathrm{m}^{-1} \mathrm{~s}^{-1}\right)$

$L=$ pipe length (m)

$R=$ pipe radius $(\mathrm{m})$.

An important concept stemming from equation 1 was the inverse relationship between $Q$ and $\mu$. Basically, if $R$ and $L$ are held constant, and there is a negligible change in $\Delta P$, then $Q$ varies inversely with changes in viscosity.

Reynolds number $\left(R_{e}\right)$ is a dimensionless ratio relating the inertial to viscous forces of a fluid (eq. 2):

$$
R_{e}=\frac{\rho V D_{H}}{\mu}
$$

where

$V=$ average velocity of the fluid through the pipe $\left(\mathrm{m} \mathrm{s}^{-1}\right)$

$\rho=$ density of the fluid $\left(\mathrm{kg} \mathrm{m}^{-3}\right)$

$D_{H}=$ hydraulic diameter of the pipe (m).

$R_{e}$ is commonly used to determine the flow regime (laminar or turbulent) of Newtonian fluids. Typical $R_{e}$ values less than 2000 are indicative of laminar flow, while flow is classified as turbulent for $R_{e}$ greater than 4000 . The flow regime in the previous research (Luck, 2010) was classified as laminar; therefore, equation 2 was used to ensure that the flow remained laminar during the proposed experiments.

The association between $\mu$ and kinematic viscosity $(v)$ is given by equation 3 :

$$
v=\frac{\mu}{\rho}
$$

where $v$ is the kinematic viscosity $\left(\mathrm{m}^{2} \mathrm{~s}^{-1}\right)$.

Initial flow rate tests were conducted at $2.76 \mathrm{MPa}$ to characterize the response of the orifice with the system operating at $5 \mathrm{~Hz}$. Specifically, the orifice flow rate versus $D C_{i}(10 \%$ to $90 \%)$ was of interest. Orifice flow rates were measured by collecting the simulated chemical as it exited the mixing chamber using graduated cylinders. To minimize collection error, cylinder sizes varied but were selected such that data were collected for a minimum of $1 \mathrm{~min}$, with cylinder graduation divisions representing $1 \%$ of the total material collected. Actual chemical flow rates were calculated by dividing the volume of orifice flow by the time recorded.

\section{Development of Chemical Metering Calibration Method \\ Compensating for Varying Fluid Properties}

A primary goal of this study was to develop a method to continually calibrate an injector or array of injectors to compensate for changes in fluid properties. For instance, a change in chemical concentrate temperature as a result of outdoor environmental conditions may require recalibration of the entire injection system. Closed-loop feedback control would have been optimal and received some thought; however, some problems were discovered that would make this approach quite challenging. Luck (2010) found that the time constant for a $20 \%$ to $80 \%$ step change in $D C_{i}$ was approximately $0.3 \mathrm{~s}$. Therefore, accurate flow rate data would be necessary at a rate of 5 to $10 \mathrm{~Hz}$ to attempt closed-loop feedback. The high operating pressures $(>2.76 \mathrm{MPa})$ and low flow rates $\left(<5 \mathrm{~mL} \mathrm{~s}^{-1}\right)$ associated with the proposed system made it difficult to find a flowmeter that would successfully generate an output signal of sufficient precision and accuracy.

Therefore, the following methods were developed to provide a calibration procedure for a set of injectors. The proposed procedure combined an individual injector calibration equation with a total system calibration factor to account for changes in injection fluid properties.

Because preliminary tests showed that the individual injector flow rate $\left(Q_{i}\right)$ response was linear with respect to the change in $D C_{i}$, the flow for each injector was modeled with equation 4:

$$
Q_{i}=a_{i} D C_{i}+b_{i}
$$

where

$a_{i}=$ calibration slope constant for injector $i$

$b_{i}=$ calibration intercept slope for injector $i$.

Equation 4 quantified the flow from the orifice at varying $D C_{i}$ (at constant frequency and pressure). Recognizing that this flow would vary inversely with some change in fluid $v$ (based on eq. 1), an injector recalibration constant $\left(C_{j}\right)$ was added to yield equation 5, where $j$ denotes that the calibration factor varied with time:

$$
Q_{i}=C_{j}\left(a_{i} D C_{i}+b_{i}\right)
$$

The constant $C_{j}$ essentially allowed for adjustment of the injector flow rate, since the physical properties of the injector (i.e., $R$ and $L$ ) were constant and the system pressure could be accurately controlled. It should be noted that the values of $a_{i}$ and $b_{i}$ would likely be specific for each injector and therefore would differ based on variances in orifice size attributed to manufacturability. Ideally, these values would be determined for each injector using a fluid of constant properties (i.e., density, viscosity) at the time of manufacture.

Next, a method for continually determining $C_{j}$ was nec- 
essary. To constantly calculate $C_{j}$, an initial value $\left(C_{1}\right)$ must first be determined based on the total flow through the system at the desired pressure. This could be accomplished by a variety of methods (e.g., a flowmeter); however, for the purposes of these experiments, the injectors were operated at $90 \% D C_{i}$ and the system flow was measured over a period of time by collecting the effluent in a graduated cylinder and dividing the volume collected by the time interval. This established the initial value $\left(C_{1}\right)$, which could be assumed as 1.0 .

As the fluid $v$ changed, additional flow measurements were taken, and a new $C_{j}$ was calculated based on the relationship shown in equation 6 :

$$
\frac{Q_{T 1}}{C_{1}}=\frac{Q_{T j}}{C_{j}}
$$

where

$Q_{T 1}=$ initial total flow (at $90 \% D C_{i}$ ) through injector $i$

$Q_{T j}=$ subsequent total flow measurements through injector $i$.

For the experiments conducted, all $Q_{T}$ values (i.e., $Q_{T i}$ or $Q_{T_{j}}$ ) were measured based on the injector operating at $90 \%$ $D C_{i}$. This was done to eliminate as much variation in measured $Q_{T i}$ values as possible. Rearranging equation 6 enabled the new calibration factor $\left(C_{j}\right)$ to be calculated, as shown in equation 7 :

$$
C_{j}=\frac{Q_{T j} C_{1}}{Q_{T 1}}
$$

The updated $C_{j}$ could then be used to modify the current operating $D C_{i}$ by rearranging equation 5 and solving for $D C_{i}$, as shown in equation 8 :

$$
D C_{i}=\frac{\left(Q_{i} / C_{j}\right)-b_{i}}{a_{i}}
$$

For an increase in $\mathrm{v}$, the value of $C_{j}$ would decrease, which would result in an increase in the $D C_{i}$ setting. Conversely, if $v$ decreased, then $C_{j}$ would increase, yielding a lower $D C_{i}$. This procedure would allow for continuous monitoring and adjustment of chemical concentrate flow from the injectors.

The calibration method was evaluated by collecting three replicated samples from the injectors at various chemical concentrate temperatures to simulate changing viscosities. Tests were conducted at a chemical pressure of $2.76 \mathrm{MPa}$ with the injector operated at $5 \mathrm{~Hz}$ and varying $D C_{i}$ values. The recalibration methodology was tested for increases and decreases in fluid temperature. Injector 1 calibration coefficients were initially developed during trial A. The fluid temperature was increased during trial B, and the recalibration factor $(C)$ was estimated for the injector. Injector 2 was used to simulate a decrease in fluid temperature where the initial injector calibration coefficients were estimated based on trial $\mathrm{A}$. The temperature was then decreased in trial B, and the correction coefficient was then estimated. Finally, injector 3 was used to estimate the ability of the recalibration technique to predict flow rates by multiple increases in fluid temperature. The initial trial (trial A) was used to develop injector operating coefficients, and subsequent trials (B to D) were used to estimate the correction coefficient. For all of these tests, variation in injector $Q_{i}$ was calculated as the standard deviation divided by the average of the flow rate data, expressed as a percentage. Errors between the actual $Q_{i}$ data versus predicted values (eq. 5) were calculated to demonstrate the effectiveness of the calibration method.

\section{Estimating Flow Rates from Multiple Injectors}

The previous section outlined methods for correcting an injector calibration equation to compensate for varying fluid properties based on individual injector $Q_{T j}$ values. In a system comprised of multiple injectors, a method for determining individual $Q_{T j}$ based on the flow through all injectors would be beneficial. As previously mentioned, flow rate differences may exist among injectors due to orifice size or solenoid valve variations. Ideally, variation could be minimized through improved manufacturing processes such that manufacturing variations could be neglected.

The variation among individual injector flow rates $\left(Q_{T i}\right)$ could be related by a calibration factor $\left(B_{i}\right)$ assuming the calibrations were carried out using a fluid with constant physical properties. The values of $B_{i}$ would therefore be provided with each injector after this initial calibration procedure. For this situation, the flow through subsequent injectors $\left(Q_{T i}\right)$ divided by $B_{i}$ would be proportional to the flow through the primary injector $\left(Q_{T 1}\right)$ divided by $B_{1}$ (assumed to be 1.0), as shown in equation 9:

$$
\frac{Q_{T 1}}{B_{1}}=\frac{Q_{T i}}{B_{i}}
$$

Rearranging equation 9 produced equation 10 to determine $B_{i}$ :

$$
B_{i}=\frac{Q_{T i} B_{1}}{Q_{T 1}}
$$

The sum of the flow rates from multiple injectors $\left(Q_{M}\right)$ is equal to the sum of the individual $Q_{T i}$ values (eq. 11):

$$
Q_{M}=\sum_{i=1}^{n} Q_{T i}
$$

If $Q_{T 1}$ (with $B_{1}$ equal to 1.0 ) were factored from the summation, equation 11 would become equation 12 :

$$
Q_{M}=Q_{T 1} \sum_{i=1}^{n}\left(1+\frac{Q_{T i}}{Q_{T 1}}\right)
$$

Recognizing that equation 10 was substituted into equation 12 for $B_{1}$ equal to 1.0 , solving for $Q_{T 1}$ yielded equation 13:

$$
Q_{T 1}=\frac{Q_{M}}{\sum_{i=1}^{n}\left(1+B_{i}\right)}
$$

Assuming $B_{i}$ values were provided, it would now be possible to estimate values of $Q_{T i}$ at any time by rearrang- 
ing equation 9 into equation 14 :

$$
Q_{T i}=\frac{Q_{T 1} B_{i}}{B_{1}}
$$

To evaluate these methods, three injectors were operated simultaneously at $90 \% D C_{i}, 5 \mathrm{~Hz}$, and $2.76 \mathrm{MPa}$. Repeated $Q_{T i}$ measurements were taken from each injector and recorded. The value of $B_{i}$ for injector 1 was set at 1.0, and the values of $B_{i}$ for injectors 2 and 3 were calculated using equation 10 based on flow data collected during trial 1 . After the chemical concentrate temperature was reduced during trial 2, two additional sets of $Q_{T i}$ measurements were taken for the three injectors. The individual injector $Q_{T}$ values were predicted for both sets of data based on equations 13 and 14 using the measured $Q_{M}$ and initial $B_{i}$ values. The variation among repeated injector flow rates was calculated as the standard deviation divided by the average of the flow rates measured, expressed as a percentage. The absolute errors between predicted $Q_{T i}$ values and measured values were then calculated.

\section{RESULTS AND DisCUSSION CHEMICAl Viscosity and PRELIMINARY INJECTION RESULTS}

Results of the chemical concentrate kinematic viscosity tests yielded equation 15 to predict the viscosity of the chemical concentrate based on varying temperatures ( $T$ in $\left.{ }^{\circ} \mathrm{C}\right)$ :

$$
v=-5.19 \times 10^{-7}(T)+2.96 \times 10^{-5}
$$

It should be noted that this equation would not necessarily apply to the actual pesticide, glyphosate; it would be valid only for the chemical concentrate used during these tests. Based on data collected by Luck (2010), it was clear that the effects of temperature on the viscosities of glyphosate and a mixture of glycerin and water were different depending on the glycerin-to-water ratio. According to results of that study, a decrease from $45^{\circ} \mathrm{C}$ to $10^{\circ} \mathrm{C}$ would result in a $400 \%$ increase in viscosity. As discussed by Luck et al. (2011), pesticide application errors are typically tolerated up to a $5 \%$ deviation from the desired application rate. Therefore, it would be possible to predict, based on temperature change (eq. 15), how much change in $v$ could be tolerated before application rate errors would exceed this threshold. An analysis of equation 15 found that a variation of $2.1{ }^{\circ} \mathrm{C}$ would result in a $5 \%$ change in $v$ for the chemical concentrate. Further examination of equation 5 showed that the same $45^{\circ} \mathrm{C}$ to $10^{\circ} \mathrm{C}$ decrease in $T$ would result in a $390 \%$ increase in $v$, nearly the same magnitude as found for glyphosate (Luck, 2010). Therefore, the chosen proportion of glycerin and DI water ( $73 \%$ and $27 \%$ by mass, respectively) in the chemical concentrate was considered an acceptable substitute for glyphosate in this study.

Preliminary flow rate tests verified the linear relationship between orifice flow rate and $D C_{i}$ (constant frequency and pressure). Figure 3 illustrates these data for the solenoid operated at $5 \mathrm{~Hz}$ with a system pressure of $2.76 \mathrm{MPa}$. The orifice flow had a positive, linear relationship with the $D C_{i}$ from $10 \%$ to $90 \%$. The flow rates ranged from an average of 0.68 to $3.21 \mathrm{~mL} \mathrm{~s}^{-1}$ at $10 \%$ and $90 \% D C$, respectively, for a turndown ratio of 4.7:1. These data indicated that the system performed similarly to previous studies (Luck, 2010). Another important point to note was that the intercept was nonzero for the calibration equation shown in figure 3. This was attributed to the mechanical limits of operating the solenoid valves at higher frequencies. The $R_{e}$ value was calculated as 594 based on the maximum flow rate from the tests in figure 3 , at a $v$ of $20 \times 10^{-6} \mathrm{~m}^{2} \mathrm{~s}^{-1}$

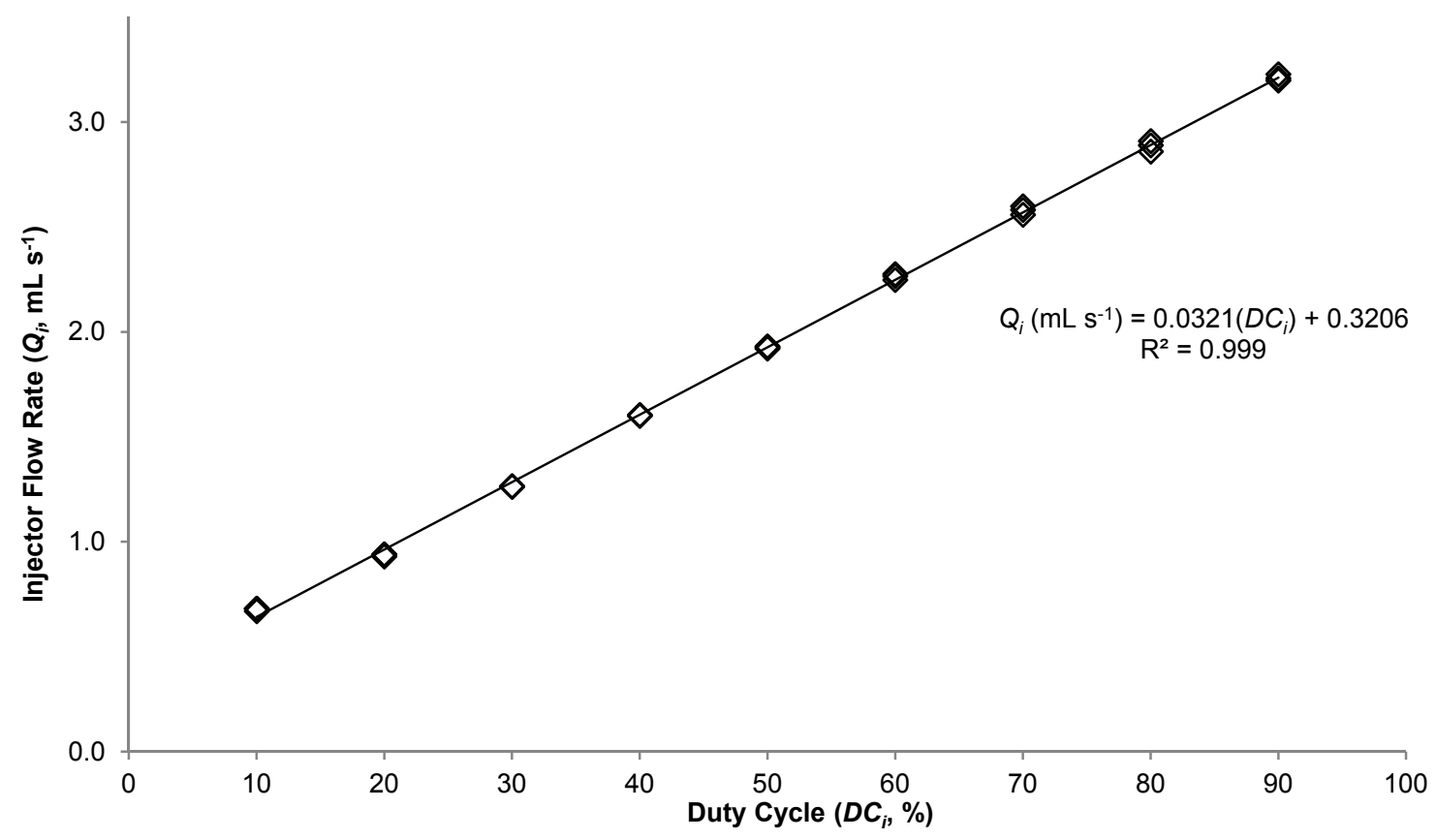

Figure 3. Flow rate versus duty cycle for injector at $2.76 \mathrm{MPa}$ and $5 \mathrm{~Hz}$. 
(chemical concentrate at $18.5^{\circ} \mathrm{C}$ ). This indicated that the flow regime was laminar.

\section{Chemical Metering Calibration Test Results Compensating for Varying Fluid Properties}

Figure 4 illustrates the calibration data for the three injectors used during the chemical metering tests. Because of the linear response in $Q_{i}$ versus $D C_{i}$ (fig. 3), three-point calibrations were conducted at $10 \%, 50 \%$, and $90 \% D C_{i}$ for each injector. The tests were conducted at laboratory temperatures $\left(19^{\circ} \mathrm{C}\right)$ for all three injectors. The data in figure 4 highlight potential injector performance variation that could be the product of two sources. Slight orifice size disparity was expected because of the manufacturing methods, as each orifice was drilled separately on a lathe. The potential also existed for variation in solenoid valve performance. It is likely that orifice size variability and inconsistent solenoid operation may have contributed to differences in $Q_{i}$ $\left(10 \%\right.$ to $\left.90 \% D C_{i}\right)$ among the three injectors (i.e., variation among $a_{i}$ and $b_{i}$ values). This could not be confirmed directly from the data collected during these experiments.

Average $Q_{i}$ values at each $D C_{i}$ setting were compared for the three injectors shown in figure 4 . The $Q_{i}$ variation was $6.7 \%, 3.5 \%$, and $3.0 \%$ for $D C_{i}$ settings of $10 \%, 50 \%$, and $90 \%$, respectively, across all three injectors. As expected, the uniformity improved as flow through the injectors increased. Coefficients of variation (CV) were calculated (e.g., standard deviation divided by average) for injector flow rates at three $D C_{i}$ values $(10 \%, 50 \%$, and $90 \%)$, which again demonstrated reduced variability in flow rates as $D C_{i}$ (and ultimately $Q_{i}$ ) increased (table 1). These data indicated that operation of the injector at a higher $D C_{i}$ would improve flow uniformity from the injectors. This could be an important factor when considering the size of the orifice required for delivering desired flow rates (and
Table 1. Summary of flow rate $\left(Q_{i}\right)$ coefficient of variation $(\mathrm{CV})$ values versus duty cycle $\left(D C_{i}\right)$ for injectors 1,2 , and 3.

\begin{tabular}{|c|c|c|c|c|c|c|}
\hline \multirow[b]{2}{*}{ Injector } & \multicolumn{2}{|c|}{$10 \% D C_{i}$} & \multicolumn{2}{|c|}{$50 \% D C_{i}$} & \multicolumn{2}{|c|}{$90 \% D C_{i}$} \\
\hline & $\begin{array}{l}\text { Avg. } Q_{i} \\
\left(\mathrm{~mL} \mathrm{~s}^{-1}\right)\end{array}$ & $\begin{array}{l}\text { CV } \\
(\%)\end{array}$ & $\begin{array}{l}\text { Avg. } Q_{i} \\
\left(\mathrm{~mL} \mathrm{~s}^{-1}\right)\end{array}$ & $\begin{array}{l}\text { CV } \\
(\%)\end{array}$ & $\begin{array}{l}\text { Avg. } Q_{i} \\
\left(\mathrm{~mL} \mathrm{~s}^{-1}\right)\end{array}$ & $\begin{array}{l}\text { CV } \\
(\%)\end{array}$ \\
\hline 1 & 0.399 & 1.2 & 1.594 & 0.1 & 2.821 & 0.2 \\
\hline 2 & 0.455 & 2.9 & 1.694 & 0.8 & 2.986 & 0.1 \\
\hline 3 & 0.436 & 0.6 & 1.694 & 0.6 & 2.950 & 0.2 \\
\hline
\end{tabular}

ultimately application rates) from the injection system. Selecting an orifice size to provide target application rates at $50 \% D C_{i}$ or higher would likely result in reduced variation for the injectors.

Tests were conducted to evaluate the proposed recalibration method for injectors based on total flow values to compensate for varying fluid viscosities. Calibration data collected for injector 1 (fig. 5) were used to simulate an increase in flow through the injector (i.e., a decrease in fluid viscosity). The initial trial (trial A) yielded calibration coefficient values for $a_{1}$ and $b_{1}$ of 0.0303 and 0.0905 , respectively. The average total flow $\left(Q_{T 1}\right)$ during trial A was $2.82 \mathrm{~mL} \mathrm{~s}^{-1} ; C_{1}$ was selected as 1.0 . The temperature of the fluid was increased by approximately $7^{\circ} \mathrm{C}$ prior to conducting trial B. The average total flow for trial B $\left(Q_{T 2}\right)$ of $3.09 \mathrm{~mL} \mathrm{~s}^{-1}$ was used with $Q_{T 1}$ and $C_{1}$ to calculate $C_{2}$ based on equation 7 . The resulting $C_{2}$ (1.096) indicated an increase in the total injector flow rate, which was expected.

The errors associated with using the proposed calibration method for injector 1 (trial B) are shown in table 2 . Adjustment of the initial calibration using $C_{2}$ to predict the injector flow rate during trial B $\left(Q_{1 \mathrm{~B}}\right)$ was compared to actual injector flow rates by calculating the error between the two. Error was calculated by differencing the predicted and actual injector flow rates and then dividing by the actual flow rate (expressed as a percentage). The error increased as $D C_{1}$ decreased, a finding that was previously noted with the flow data in table 1 .

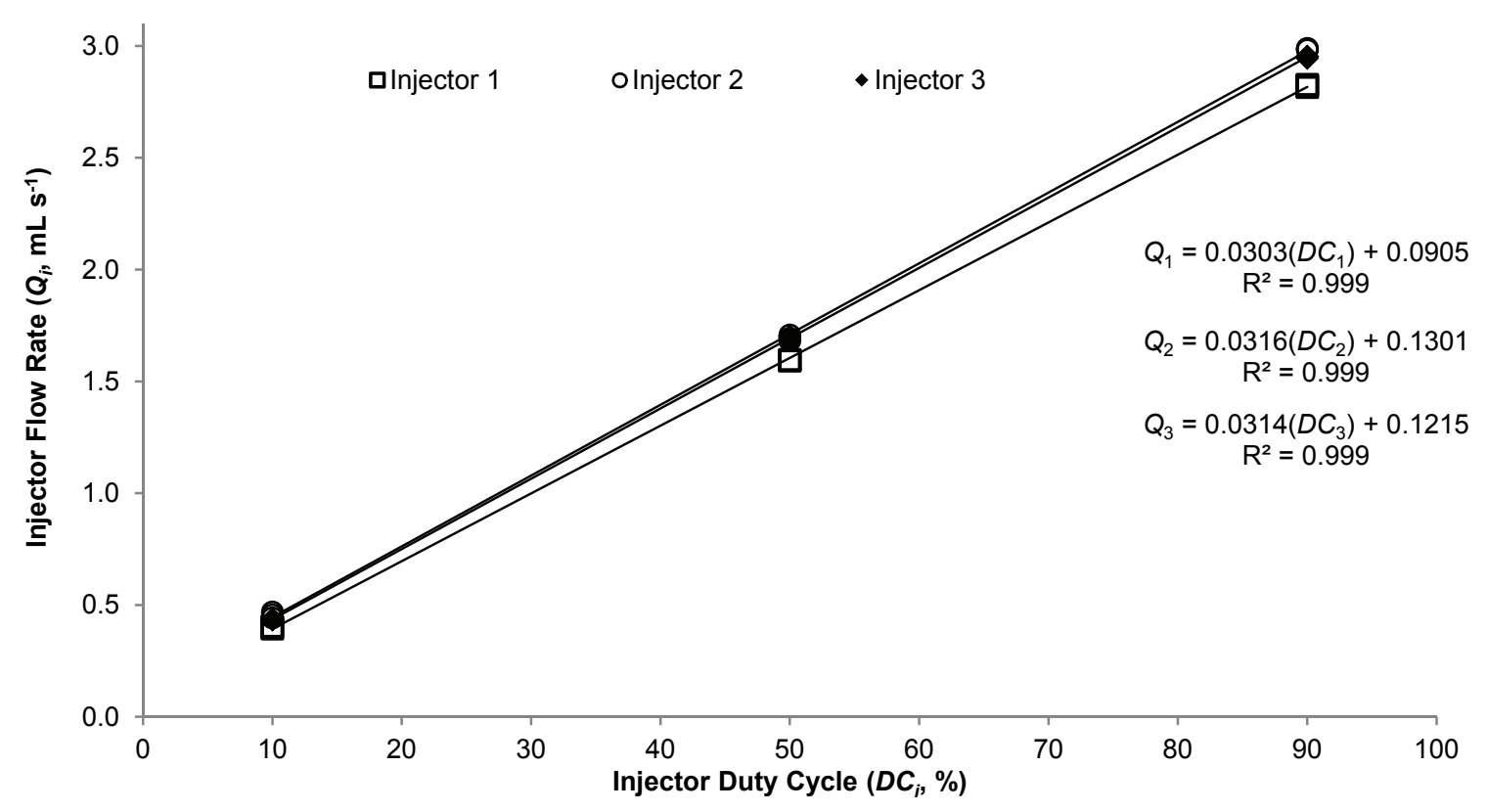

Figure 4. Flow rate $\left(Q_{i}\right)$ versus duty cycle $\left(D C_{i}\right)$ for three injectors. 


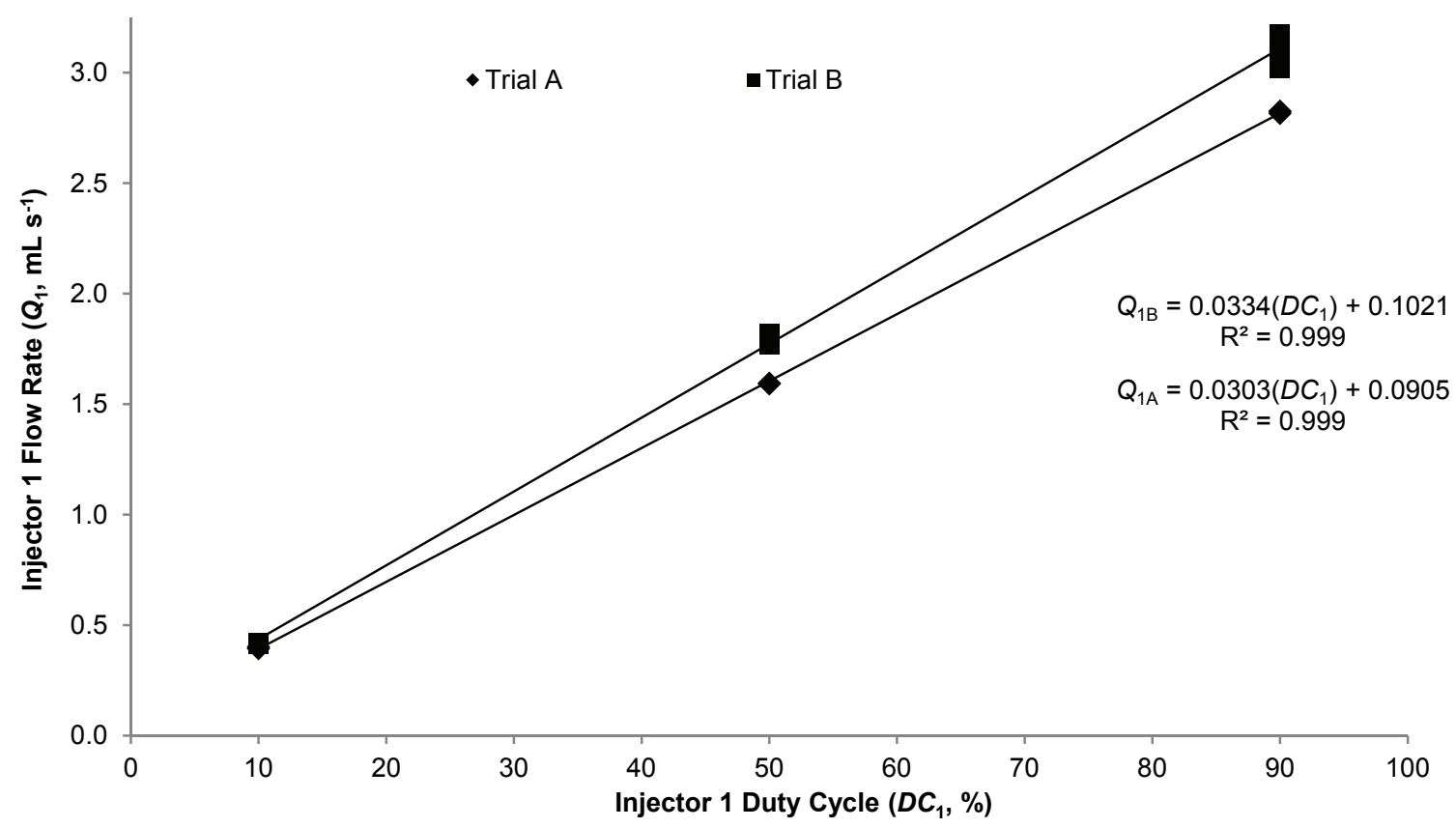

Figure 5. Injector 1 flow rate $\left(Q_{1}\right)$ versus duty cycle $\left(D C_{1}\right)$ as fluid temperature increased from trial $\mathrm{A}$ to $\mathrm{B}$.

Table 2. Summary of injector 1 flow rate errors using proposed recalibration method after an increase in fluid temperature (trial B).

\begin{tabular}{cccc}
\hline$D C_{1}$ & $\begin{array}{c}\text { Predicted } Q_{1 \mathrm{~B}} \\
\left(\mathrm{~mL} \mathrm{~s}^{-1}\right)\end{array}$ & $\begin{array}{c}\text { Actual } Q_{1 \mathrm{~B}} \\
\left(\mathrm{~mL} \mathrm{~s}^{-1}\right)\end{array}$ & $\begin{array}{c}\text { Error } \\
(\%)\end{array}$ \\
\hline 10 & 0.43 & 0.42 & 3.4 \\
50 & 1.76 & 1.79 & 1.6 \\
90 & 3.09 & 3.09 & 0.1 \\
\hline
\end{tabular}

To simulate a decrease in flow through the injector (increase in fluid viscosity), calibration data were collected for injector 2 (fig. 6). The initial trial (trial A) yielded calibration coefficient values for $a_{1}$ and $b_{1}$ of 0.0343 and 0.1429 , respectively. The average total flow $\left(Q_{T 1}\right)$ during trial $\mathrm{A}$ was $3.23 \mathrm{~mL} \mathrm{~s}^{-1} ; C_{1}$ was again selected as 1.0 . The temperature of the fluid was allowed to decrease by approximately $7^{\circ} \mathrm{C}$ prior to conducting trial $\mathrm{B}$. The average total flow for trial B $\left(Q_{T 2}\right)$ of $2.99 \mathrm{~mL} \mathrm{~s}^{-1}$ was used with $Q_{T 1}$ and $C_{1}$ to calculate $C_{2}$ using equation 7 . The resulting $C_{2}$ (0.924) indicated a decrease in the injector flow rate, as

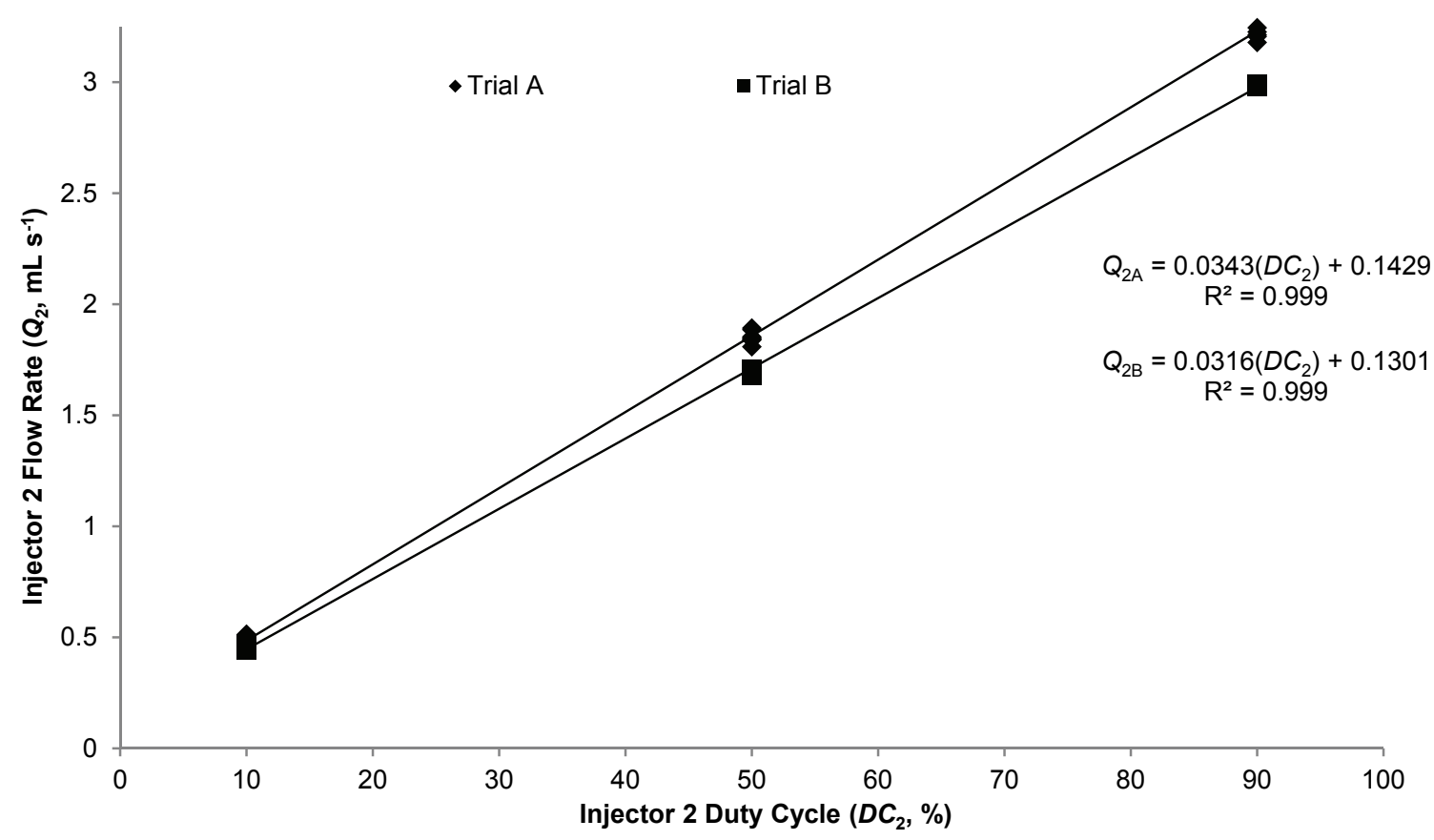

Figure 6. Injector 2 flow rate $\left(Q_{2}\right)$ versus duty cycle $\left(D C_{2}\right)$ as fluid temperature decreased from trial A to $\mathrm{B}$. 
Table 3. Summary of injector 2 flow rate errors using proposed calibration method after a decrease in fluid temperature (trial B).

\begin{tabular}{cccc}
\hline$D C_{2}$ & $\begin{array}{c}\text { Predicted } Q_{2 \mathrm{~B}} \\
\left(\mathrm{~mL} \mathrm{~s}^{-1}\right)\end{array}$ & $\begin{array}{c}\text { Actual } Q_{2 \mathrm{~B}} \\
\left(\mathrm{~mL} \mathrm{~s}^{-1}\right)\end{array}$ & $\begin{array}{c}\text { Error } \\
(\%)\end{array}$ \\
\hline 10 & 0.45 & 0.46 & 1.4 \\
50 & 1.72 & 1.69 & 1.3 \\
90 & 2.98 & 2.99 & 0.1 \\
\hline
\end{tabular}

anticipated.

The errors associated with using the proposed calibration method for injector 2 (trial B) are shown in table 3 . Adjustment of the initial calibration using $C_{2}$ to predict the injector flow rate during trial $\mathrm{B}\left(Q_{2 \mathrm{~B}}\right)$ yielded promising results for injector flow rate reductions. The errors were slightly less than those calculated for injector 1 , and as expected, errors between the predicted and measured $Q_{2 \mathrm{~B}}$ values decreased as $D C_{2}$ increased.

To simulate a multipoint change in flow through an injector, calibration data were collected at four different temperatures for injector 3 (fig. 7). The initial trial (trial A) produced calibration coefficient values for $a_{1}$ and $b_{1}$ of 0.0294 and 0.1082 , respectively. The average total flow $\left(Q_{T 1}\right)$ during trial A (average $T$ of $14.5^{\circ} \mathrm{C}$ ) was $2.76 \mathrm{~mL} \mathrm{~s}^{-1}$, with $C_{1}$ selected as 1.0 . The temperature of the fluid was increased to $19.2^{\circ} \mathrm{C}$ prior to trial B. The average $Q_{T 2}$ value was $2.95 \mathrm{~mL} \mathrm{~s}^{-1}$, which yielded a $C_{2}$ value of 1.069 using $Q_{T 1}$ and $C_{1}$ in equation 7. The chemical concentrate temperature was increased to $24.8^{\circ} \mathrm{C}$ before commencing with trial C. The resulting average $Q_{T 3}$ value was $3.21 \mathrm{~mL} \mathrm{~s}^{-1}$ for the data collected, which produced a value of 1.163 for $C_{3}$.
Table 5. Summary of injector 3 flow rate errors using proposed calibration method for multiple decreases in fluid temperature.

\begin{tabular}{cccccc}
\hline & $\begin{array}{c}\text { Predicted } \\
Q_{3 \mathrm{~A}} \\
\left(\mathrm{~mL} \mathrm{~s}^{-1}\right)\end{array}$ & $\begin{array}{c}\text { Actual } \\
Q_{3 \mathrm{~A}} \\
\left(\mathrm{~mL} \mathrm{~s}^{-1}\right)\end{array}$ & $\begin{array}{c}\text { Trial A } \\
\text { Error } \\
(\%)\end{array}$ & $\begin{array}{c}\text { Trial B } \\
\text { Error } \\
(\%)\end{array}$ & $\begin{array}{c}\text { Trial C } \\
\text { Error } \\
(\%)\end{array}$ \\
\hline 10 & 0.40 & 0.41 & 2.2 & 2.6 & 3.0 \\
50 & 1.58 & 1.57 & 0.7 & 0.1 & 0.2 \\
90 & 2.77 & 2.76 & 0.4 & 0.4 & 0.4 \\
\hline
\end{tabular}

Trial D consisted of data collected with a chemical temperature at $35.3^{\circ} \mathrm{C}$, which yielded $Q_{T 4}$ equal to $3.34 \mathrm{~mL} \mathrm{~s}^{-1}$ and a $C_{4}$ value of 1.210 .

The errors associated with using the proposed calibration method for injector 3 (trials B, C, and D) are shown in table 4. Errors between the predicted and measured flow rates $\left(Q_{3 \mathrm{~B}}\right.$ and $\left.Q_{3 \mathrm{C}}\right)$ were similar when calibration factors $C_{2}$ and $C_{3}$ were used to adjust the initial injector calibration equation. In this situation, the flow rate increased $21 \%$ from trial A to trial D. The errors followed the same trend previously noted with $D C_{i}$ and were of the same magnitude as seen with the test using injector 2. These data indicated that recalibrating for multiple changes in fluid viscosity could be possible based on the proposed methodology.

Using the same data, trial D was chosen as the initial calibration $\left(C_{4}\right.$ equal to 1.0$)$ to compare errors resulting from the multipoint recalibration technique in the event that flow rates decreased due to fluid viscosity changes. This case represented a flow rate decrease of $17.4 \%$ from trial D to trial A. The results of this analysis are summarized in table 5. Resulting calibration factors were $0.826,0.833$, and

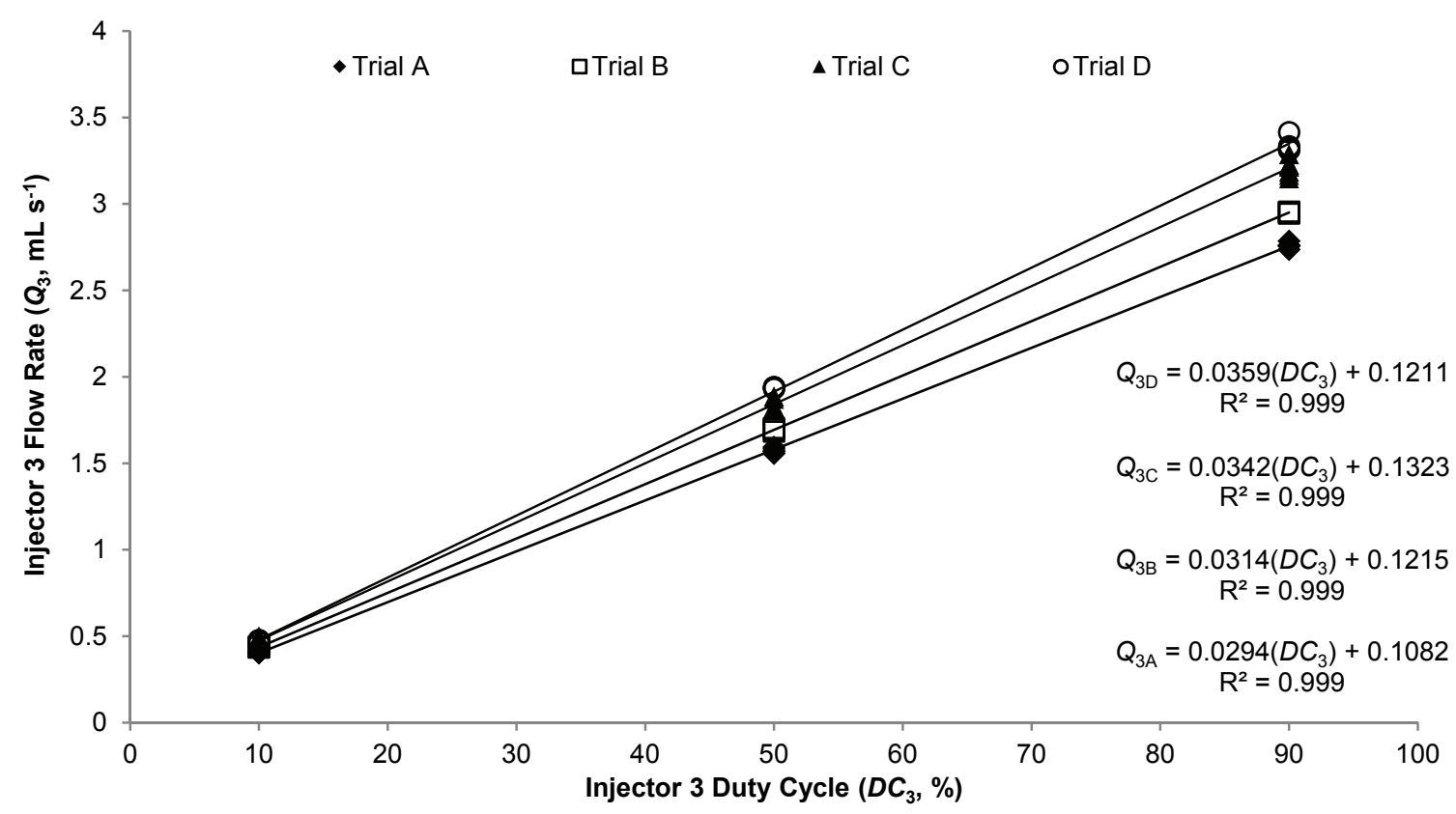

Figure 7. Injector 3 flow rate $\left(Q_{3}\right)$ versus duty cycle $\left(D C_{3}\right)$ as fluid temperature was increased from trial $A$ through $D$.

Table 4. Summary of injector 3 flow rate errors using proposed calibration method after multiple increases in fluid temperature (trials B to D).

\begin{tabular}{|c|c|c|c|c|c|c|c|c|c|}
\hline \multirow[b]{2}{*}{$D C_{3}$} & \multicolumn{3}{|c|}{ Trial B } & \multicolumn{3}{|c|}{ Trial C } & \multicolumn{3}{|c|}{ Trial D } \\
\hline & $\begin{array}{l}\text { Predicted } Q_{3 \mathrm{~B}} \\
\quad\left(\mathrm{~mL} \mathrm{~s}^{-1}\right)\end{array}$ & $\begin{array}{l}\text { Actual } Q_{3 \mathrm{~B}} \\
\left(\mathrm{~mL} \mathrm{~s}^{-1}\right)\end{array}$ & $\begin{array}{c}\text { Error } \\
(\%)\end{array}$ & $\begin{array}{l}\text { Predicted } Q_{3 \mathrm{C}} \\
\quad\left(\mathrm{mL} \mathrm{s}^{-1}\right)\end{array}$ & $\begin{array}{l}\text { Actual } Q_{3 \mathrm{C}} \\
\left(\mathrm{mL} \mathrm{s}^{-1}\right)\end{array}$ & $\begin{array}{c}\text { Error } \\
(\%)\end{array}$ & $\begin{array}{l}\text { Predicted } Q_{3 \mathrm{D}} \\
\quad\left(\mathrm{mL} \mathrm{s}^{-1}\right)\end{array}$ & $\begin{array}{l}\text { Actual } Q_{3 \mathrm{D}} \\
\left(\mathrm{mL} \mathrm{s}^{-1}\right)\end{array}$ & $\begin{array}{c}\text { Error } \\
(\%)\end{array}$ \\
\hline 10 & 0.43 & 0.44 & 1.3 & 0.47 & 0.48 & 1.7 & 0.49 & 0.47 & 3.3 \\
\hline 50 & 1.69 & 1.69 & 0.4 & 1.84 & 1.84 & 0.2 & 1.91 & 1.94 & 1.3 \\
\hline 90 & 2.94 & 2.95 & 0.2 & 3.20 & 3.21 & 0.2 & 3.33 & 3.34 & 0.2 \\
\hline
\end{tabular}


0.961 for trials A, B, and C, respectively. Errors between predicted $Q_{3}$ values increased slightly when the calibration procedure was carried out for reduced flow rates resulting from viscosity increases. However, the maximum error (trial C) was only $3 \%$ at $10 \% D C_{i}$, and as previously demonstrated, errors were much less at higher $D C_{i}$. Therefore, the recalibration method produced acceptable results ( $<5 \%$ error) when used to compensate for increases or decreases in fluid viscosity.

\section{Estimating Flow Rates from Multiple Injectors}

Initial flow rate tests (constant fluid temperature) yielded average $Q_{T i}$ values of $3.01,2.96$, and $3.13 \mathrm{~mL} \mathrm{~s}^{-1}$ for injectors 1,2 , and 3 , respectively. For the purpose of these tests, $3.01 \mathrm{~mL} \mathrm{~s}^{-1}$ was selected as the target injection rate for this system. Therefore, $B_{1}$ was selected as 1.0 based on this flow rate through injector 1 . It should be noted that, in reality, a situation may exist in which none of the available injector $B_{i}$ values would be equal to 1.0. In this case, all $B_{i}$ values could be divided by one selected $B_{i}$. The selected $B_{i}$ would become 1.0 (i.e., $B_{1}$ ), and the calibration method could proceed with $Q_{T i}$ values being determined relative to the new $B_{1}$. Equation 10 was then used to estimate values for $B_{2}$ and $B_{3}$, which were found to be 0.981 and 1.039 , respectively.

Injector flow rate data for trial 1 are shown in table 6 . The predicted $Q_{T i}$ values calculated based on the initial $B_{i}$ for each injector with $Q_{M}$ produced a small amount of error when compared to actual $Q_{T i}$ values during trial 1. Errors ranged from $0.23 \%$ to $0.66 \%$ of $Q_{T i}$ for the three injectors.

Trial 2 was conducted after a reduction in the chemical concentrate temperature. Based on the initial calibration, $B_{i}$ values remained 1.0, 0.981, and 1.039 for injectors 1,2 , and 3, respectively. A summary of the error analysis for trial 2 is shown in table 7. Overall, the error in predicting $Q_{T i}$ values decreased for trial 2 when compared to trial 1 . The maximum average absolute error was only $0.42 \%$.
The analysis presented in this portion of the study provided evidence that it was possible to predict flow values based on initial calibration factors for each injector. Assuming $B_{i}$ values could be provided for each injector based on a target injection rate, it would be possible to predict (with less than $0.66 \%$ error), the flow through each injector based on the sum of the injector flow rates. The significance of this method is that the values of $Q_{T i}$ found here could be substituted into equation 7 (as $Q_{T_{j}}$ ) when recalculating $C_{j}$.

\section{CONClusions}

The primary objective of this study was to develop a method for continuous recalibration of chemical injectors should some change (e.g., kinematic viscosity) to the chemical concentrate occur. Because a suitable flowmeter was not readily available to provide adequate feedback for a single injector, this recalibration procedure was necessary so that the injectors could operate in an open-loop configuration with higher accuracy. Changes in chemical temperature affect fluid viscosity, and ultimately the flow rates through the injectors barring some form of compensation. A procedure was developed to constantly modify the initial injector calibration equation using a coefficient, $C_{j}$. The value for $C_{j}$ was calculated based on changes in the injector flow rates at a constant operating duty cycle, $D C_{i}(90 \%)$. Test results indicated that this method was able to compensate for changes in fluid kinematic viscosity (from temperature changes and/or product variation). Errors were less than $3.4 \%$ for the minimum $D C_{i}(10 \%)$ and dropped to $0.2 \%$ for the maximum $D C_{i}(90 \%)$ for temperature changes of up to $20^{\circ} \mathrm{C}$. While larger temperature changes may be expected, these test results showed that the proposed method could be successfully implemented to meet desired injection rates. Because multiple injectors would be used in

Table 6. Summary of errors between actual and predicted injector flow rates for initial calibration sequence (trial 1) of multiple injectors.

\begin{tabular}{|c|c|c|c|c|c|c|c|c|c|}
\hline \multicolumn{4}{|c|}{ Actual Flow Data } & \multicolumn{3}{|c|}{ Predicted Flow Data } & \multicolumn{3}{|c|}{ Error } \\
\hline $\begin{array}{c}Q_{T 1} \\
\left(\mathrm{~mL} \mathrm{~s}^{-1}\right)\end{array}$ & $\begin{array}{c}Q_{T 2} \\
\left(\mathrm{~mL} \mathrm{~s}^{-1}\right)\end{array}$ & $\begin{array}{c}Q_{T 3} \\
\left(\mathrm{~mL} \mathrm{~s}^{-1}\right)\end{array}$ & $\begin{array}{c}Q_{M} \\
\left(\mathrm{~mL} \mathrm{~s}^{-1}\right)\end{array}$ & $\begin{array}{c}Q_{T 1} \\
\left(\mathrm{~mL} \mathrm{~s}^{-1}\right)\end{array}$ & $\begin{array}{c}Q_{T 2} \\
\left(\mathrm{~mL} \mathrm{~s}^{-1}\right)\end{array}$ & $\begin{array}{c}Q_{T 3} \\
\left(\mathrm{~mL} \mathrm{~s}^{-1}\right)\end{array}$ & $\begin{array}{l}Q_{T 1} \\
(\%)\end{array}$ & $\begin{array}{l}Q_{T 2} \\
(\%)\end{array}$ & $\begin{array}{l}Q_{T 3} \\
(\%)\end{array}$ \\
\hline 3.07 & 3.16 & 3.31 & 9.53 & 3.10 & 3.16 & 3.28 & 0.78 & 0.01 & 0.74 \\
\hline 3.07 & 3.16 & 3.29 & 9.52 & 3.09 & 3.15 & 3.28 & 0.61 & 0.16 & 0.41 \\
\hline 3.08 & 3.15 & 3.30 & 9.52 & 3.09 & 3.15 & 3.28 & 0.42 & 0.19 & 0.57 \\
\hline 3.06 & 3.14 & 3.29 & 9.50 & 3.09 & 3.14 & 3.27 & 0.80 & 0.02 & 0.76 \\
\hline 3.09 & 3.14 & 3.30 & 9.53 & 3.09 & 3.15 & 3.28 & 0.24 & 0.54 & 0.74 \\
\hline 3.10 & 3.19 & 3.35 & 9.64 & 3.13 & 3.19 & 3.32 & 0.93 & 0.19 & 1.03 \\
\hline 3.12 & 3.18 & 3.33 & 9.63 & 3.13 & 3.19 & 3.31 & 0.30 & 0.13 & 0.41 \\
\hline 3.16 & 3.20 & 3.37 & 9.73 & 3.16 & 3.22 & 3.35 & 0.07 & 0.61 & 0.64 \\
\hline & & & & & & & 0.52 & 0.23 & 0.66 \\
\hline
\end{tabular}

Table 7. Summary of errors between actual and predicted injector flow rates for recalibration sequence after decreasing the fluid temperature (trial 2) of multiple injectors.

\begin{tabular}{|c|c|c|c|c|c|c|c|c|c|}
\hline \multicolumn{4}{|c|}{ Actual Flow Data } & \multicolumn{3}{|c|}{ Predicted Flow Data } & \multicolumn{3}{|c|}{ Error } \\
\hline $\begin{array}{c}Q_{T 1} \\
\left(\mathrm{~mL} \mathrm{~s}^{-1}\right)\end{array}$ & $\begin{array}{c}Q_{T 2} \\
\left(\mathrm{~mL} \mathrm{~s}^{-1}\right)\end{array}$ & $\begin{array}{c}Q_{T 3} \\
\left(\mathrm{~mL} \mathrm{~s}^{-1}\right)\end{array}$ & $\begin{array}{c}Q_{M} \\
\left(\mathrm{~mL} \mathrm{~s}^{-1}\right)\end{array}$ & $\begin{array}{c}Q_{T 1} \\
\left(\mathrm{~mL} \mathrm{~s}^{-1}\right)\end{array}$ & $\begin{array}{c}Q_{T 2} \\
\left(\mathrm{~mL} \mathrm{~s}^{-1}\right)\end{array}$ & $\begin{array}{c}Q_{T 3} \\
\left(\mathrm{~mL} \mathrm{~s}^{-1}\right)\end{array}$ & $\begin{array}{c}Q_{T 1} \\
\left(\mathrm{~mL} \mathrm{~s}^{-1}\right)\end{array}$ & $\begin{array}{c}Q_{T 2} \\
\left(\mathrm{~mL} \mathrm{~s}^{-1}\right)\end{array}$ & $\begin{array}{c}Q_{T 3} \\
\left(\mathrm{~mL} \mathrm{~s}^{-1}\right)\end{array}$ \\
\hline 2.98 & 3.02 & 3.15 & 9.15 & 2.97 & 3.03 & 3.15 & 0.17 & 0.35 & 0.18 \\
\hline 2.98 & 3.02 & 3.17 & 9.18 & 2.98 & 3.04 & 3.16 & 0.04 & 0.43 & 0.45 \\
\hline 2.96 & 3.00 & 3.14 & 9.10 & 2.96 & 3.01 & 3.13 & 0.25 & 0.40 & 0.14 \\
\hline 2.95 & 3.01 & 3.16 & 9.13 & 2.96 & 3.02 & 3.14 & 0.45 & 0.31 & 0.72 \\
\hline 2.99 & 3.02 & 3.15 & 9.16 & 2.97 & 3.03 & 3.15 & 0.49 & 0.44 & 0.05 \\
\hline 2.98 & 3.01 & 3.19 & 9.19 & 2.98 & 3.04 & 3.16 & 0.02 & 1.02 & 0.97 \\
\hline \multirow[t]{2}{*}{2.99} & 3.05 & 3.17 & 9.21 & 2.99 & 3.05 & 3.17 & 0.10 & 0.08 & 0.17 \\
\hline & & & & & & & 0.24 & 0.42 & 0.40 \\
\hline
\end{tabular}


commercial deployment of this technology, a method was developed to calculate the required injector flow rates $\left(Q_{T i}\right)$ using initial injector calibration factors $\left(B_{i}\right)$ based on a target flow rate. Using this recalibration method for multiple injectors, errors ranged from $0.23 \%$ to $0.66 \%$ between predicted and actual flow rates for all three injectors.

Temperature changes during pesticide application would affect the kinematic viscosity and ultimately the flow rate of the chemical through the injectors for the proposed system. As previously mentioned, the high-pressure, low-flow demands of the proposed system did not allow for a method of accurate, closed-loop feedback to be developed for a single injector. Instead, the open-loop operation envisioned for the system could be continually recalibrated using the methods developed in this study. Recalibration of the injectors at intervals ranging from 1 to 2 min would likely be possible based on this approach. This would provide adequate compensation to reduce the effects of temperature change in the injection system while simultaneously allowing the injectors to respond quickly to desired changes in application rates (e.g., from sprayer acceleration or target rate changes).

\section{ACKNOWLEDGEMENTS}

This material is based on work supported by the USDA Cooperative State Research, Education, and Extension Service (CSREES) under Agreement No. 2009-0720-1146. Any opinions, findings, conclusions, or recommendations expressed in this publication are those of the authors and do not necessarily reflect the views of the USDA.

\section{REFERENCES}

Anglund, E. A., \& Ayers, P. D. (2003). Field evaluation of response times for a variable-rate (pressure-based and injection) liquid chemical applicator. Appl. Eng. Agric., 19(3), 273-282. http://dx.doi.org/10.13031/2013.13659

Chi, L., Kushwaha, R. W., \& Bigsby, F. W. (1988). Chemical flow rate control in injection-type sprayers. Canadian Agric. Eng., 30(1), 19-26.

Chi, L., Kushwaha, R. W., \& Bigsby, F. W. (1989). Chemical flow rate control for an injection-type sprayer. Appl. Eng. Agric., 5(3), 339-343. http://dx.doi.org/10.13031/2013.26524

Cochran, D. L., Threadgill, E. D., \& Law, S. E. (1987). Physical properties of three oils and oil-insecticide formulations used in agriculture. Trans. ASAE, 30(5), 1338-1342. http://dx.doi.org/10.13031/2013.30567

Frost, A. R. (1990). A pesticide injection metering system for use on agricultural spraying machines. J. Agric. Eng. Res., 46, 5570. http://dx.doi.org/10.1016/S0021-8634(05)80113-1

Gebhardt, M. R., Kliethermes, A. R., \& Goering, C. E. (1984). Metering concentrated pesticides. Trans. ASAE, 27(1), 18-23. http://dx.doi.org/10.13031/2013.32726

Hughes, K. L., \& Frost, A. R. (1985). A review of agricultural spray metering. J. Agric. Eng. Res., 32, 197-207. http://dx.doi.org/10.1016/0021-8634(85)90080-0

Koo, Y. M., \& Kuhlman, D. K. (1993). A variable flow nozzle with consistent spray performance. Trans. ASAE, 36(3), 685-690. http://dx.doi.org/10.13031/2013.28386

Larson, G. H., Kuhlman, D. K., \& TenEyck, G. (1982). Direct metering of pesticide concentrations. ASAE Paper No. MC 82134. St. Joseph, Mich.: ASAE.
Luck, B. D. (2010). Development of a single-nozzle, high-pressure liquid pesticide metering and injection system. MS thesis. Lexington, Ky.: University of Kentucky, Department of Biosystems and Agricultural Engineering.

Luck, J. D. (2012). Development of a variable-orifice spray nozzle with high-pressure chemical injection for improved pesticide efficacy. PhD diss. Lexington, Ky.: University of Kentucky, Department of Biosystems and Agricultural Engineering.

Luck, J. D., Sharda, A., Pitla, S. K., Fulton, J. P., \& Shearer, S. A. (2011). A case study concerning the effects of controller response and turning movements on application rate uniformity with a self-propelled sprayer. Trans. ASABE, 54(2), 423-431. http://dx.doi.org/10.13031/2013.36445

Luck, J. D., Shearer, S. A., Luck, B. D., \& Payne, F. A. (2012). Evaluation of a Rhodamine-WT dye/glycerin mixture as a tracer for testing direct injection systems on agricultural sprayers. Appl. Eng. Agric., 28(5), 643-646. http://dx.doi.org/10.13031/2013.42424

Miller, M. S., \& Smith, D. B. (1992). A direct nozzle injection controlled rate spray boom. Trans. ASABE, 35(3), 781-785. http://dx.doi.org/10.13031/2013.28662

Qui, W., Watkins, G. A., Sobolik, C. J., \& Shearer, S. A. (1998). A feasibility study of direct injection for variable-rate herbicide application. Trans. ASAE, 41(2), 291-299. http://dx.doi.org/10.13031/2013.17174

Ramsdale, B. K., Messersmith, C. G., \& Nalewaja, J. D. (2003). Spray volume, formulation, ammonium sulfate, and nozzle effects on glyphosate efficiency. Weed Tech., 17(3), 589-598. http://dx.doi.org/10.1614/WT02-157

Reichard, D. L., \& Ladd, T. L. (1983). Pesticide injection and transfer system for field sprayer. Trans. ASAE, 26(3), 683-686. http://dx.doi.org/10.13031/2013.34002

Rockwell, A. D., \& Ayers, P. D. (1996). A variable-rate, direct nozzle injection field sprayer. Appl. Eng. Agric., 12(5), 531-538. http://dx.doi.org/10.13031/2013.25680

Steward, B. L., \& Humburg, D. S. (2000). Modeling the Raven SCS-700 chemical injection system with carrier control with sprayer simulation. Trans. ASAE, 43(2), 231-245. http://dx.doi.org/10.13031/2013.2698

Sudduth, K. A., Borgelt, S. C., \& Hou, J. (1995). Performance of a chemical injection sprayer system. Appl. Eng. Agric., 11(3), 343348. http://dx.doi.org/10.13031/2013.25747

Sumner, H. R., Rains, G. C., \& Sumner, P. E. (2000). String collectors to determine lag time of injection sprayers. Appl. Eng. Agric., 16(5), 471-476. http://dx.doi.org/10.13031/2013.5296

Tompkins, F. D., Howard, K. D., Mote, C. R., \& Freeland, R. S. (1990). Boom flow characteristics with direct chemical injection. Trans. ASAE, 33(3), 737-743. http://dx.doi.org/10.13031/2013.31394

Vidrine, C. G., Goering, C. E., Day, C. L., Gebhardt, M. R., \& Smith, D. B. (1975). A constant pesticide application rate sprayer model. Trans. ASAE, 18(3), 439-443. http://dx.doi.org/10.13031/2013.36606

Vondricka, J., \& Schulze Lammers, P. (2009a). Evaluation of a carrier control valve for a direct nozzle injection system. Biosyst. Eng., 103(1), 43-48.

http://dx.doi.org/10.1016/j.biosystemseng.2009.02.008

Vondricka, J., \& Schulze Lammers, P. (2009b). Real-time controlled direct injection system for precision farming. Precision Agric., 10(5), 421-430. http://dx.doi.org/10.1007/s11119-008-9093-x

Way, T. R., Von Bargen, K., Grisso, R. D., \& Bashford, L. L. (1991). Flowmeters for liquid herbicide formulations. Trans. ASAE, 34(2), 379-384. http://dx.doi.org/10.13031/2013.31672

Way, T. R., Von Bargen, K., Grisso, R. D., \& Bashford, L. L. (1992). Simulation of chemical application accuracy for 
injection sprayers. Trans. ASAE, 35(4), 1141-1149. http://dx.doi.org/10.13031/2013.28712

Womac, A. R., Valcore, D. L., \& Maynard II, R. A. (2002).

Variable-concentration direct injection from fixed-ratio diluentdriven pumps. Trans. ASAE, 45(6), 1721-1728.

http://dx.doi.org/10.13031/2013.11418

Zhu, H., Fox, R. D., Ozkan, H. E., Brazee, R. D., \& Derksen, R. C. (1998a). A system to determine lag time and mixture uniformity for inline injection sprayers. Appl. Eng. Agric., 14(2), 103-110. http://dx.doi.org/10.13031/2013.19369

Zhu, H., Fox, R. D., Ozkan, H. E., Brazee, R. D., \& Derksen, R. C. (1998b). Mixture uniformity in supply lines and spray patterns of a laboratory injection sprayer. Appl. Eng. Agric., 14(3), 223230. http://dx.doi.org/10.13031/2013.19380

Zhu, H., Fox, R. D., Ozkan, H. E., Brazee, R. D., \& Derksen, R. C. (1998c). Time delay for injection sprayers. Trans. ASAE, 41(3), 525-530. http://dx.doi.org/10.13031/2013.17208 